\title{
KATE CHOPIN E A LIBERTAÇÃO FEMININA
}

\author{
Rudião Rafael Wisniewski
}

\begin{abstract}
RESUMO: O presente artigo objetiva mostrar como Kate Chopin se valia de recursos linguísticodiscursivos para transmitir seus ideais de igualdade e liberdade femininas. Também se analisa a origem da família para descobrir o momento em que iniciou a hegemonia masculina. Vivendo em uma época em que a mulher tinha poucos direitos, Chopin precisou fazer do leitor seu parceiro no intuito de despertar as mulheres sobre a injusta posição a elas imposta pela sociedade patriarcal. Para exemplificar os recursos utilizados pela autora elegeu-se o conto The Story of an Hour. Um paralelo com o romance $O$ despertar será traçado para elucidar o conto, cujos fatos revelam a consciência hegemônica contra a qual Chopin lutou, inspirando gerações futuras de escritoras e feministas.
\end{abstract}

PALAVRAS-CHAVE: Kate Chopin. Libertação feminina. The Story of An hour.

ABSTRACT: This paper aims at showing how Kate Chopin relied on linguistic and discursive resources to transmit her ideals of women's equality and freedom. It is also analyzed the origin of the family to discover when the male dominance started. Living in a time when women had few rights, Chopin had to make the reader his partner in order to awake women from the unfair position imposed on them by patriarchal society. To illustrate the resources used by the author it was elected the short story The Story of an Hour. A parallel is drawn with The Awakening to clarify that short story, for what happens in its plot reveals the hegemonic consciousness which Chopin fought against, inspiring future generations of writers and feminists.

KEYWORDS: Kate Chopin. Women's liberation. The Story of An Hour.

\section{INTRODUÇÃO}

Katherine O’Flaherty Chopin (1851-1904), escritora norte-americana que ficou conhecida nos meios jornalísticos da sua época através da publicação de coletâneas de contos - Bayou Folk (1894) e A Night in Acadie (1897) - surpreendeu o público e a crítica com o romance The Awakening (1899), traduzido como O Despertar, obra arrojada e questionadora, caracterizada pelas posturas ligadas à celebração da individualidade, do erotismo e da libertação feminina, e, por esse motivo, duramente criticada. Sua obra completa, incluindo contos nunca antes publicados, foi organizada e publicada apenas em 2002, pela The Library 
of América. Nela estão uns dos melhores e mais conhecidos contos da autora - difundidos pela internet - como The Story of An Hour e A Pair of Silk Stockings.

Kate foi casada com Oscar Chopin de 1870 a 1882, quando este morreu de febre tifoide. Com seis filhos para criar ela retorna à casa dos pais e, incentivada por amigos, começa escrever para aumentar sua renda. Não fosse a morte de Oscar, o mundo jamais conheceria a brilhante obra dessa autora que inspirou muitas escritoras e continua sendo admirada e cultuada por muitas mulheres - e alguns homens.

\section{ORIGEM DA FAMÍLIA}

Na obra A origem da família, da propriedade privada e do Estado, em que discute a evolução das três formas principais de matrimônio, Engels (1985:81) relaciona-as, estabelecendo uma correspondência aos três estágios fundamentais da evolução burguesa: "ao estado selvagem corresponde o matrimônio por grupos, à barbárie, o matrimônio sindiásmico, e à civilização corresponde a monogamia com seus complementos: o adultério e a prostituição".

O filósofo acentua que a primeira forma de matrimônio da humanidade, ou melhor, na sua passagem da animalidade à humanidade, foi o matrimônio por grupos, um período de promiscuidade em que grupos inteiros de homens e mulheres pertenciam uns aos outros.

A família consanguínea representou a primeira etapa da organização familiar, com grupos conjugais classificados por gerações, sendo a primeira geração, equivalente aos avôs e avós, maridos e mulheres entre si. A segunda geração, pais e mães, também eram maridos e mulheres entre si, e assim sucessivamente entre as gerações seguintes. Nesse tipo de família, uma geração não podia manter relação sexual com a outra, mas primos, primas, irmãos e irmãs eram maridos e mulheres entre si.

A segunda etapa da organização familiar, mais difícil de se processar, devido à maior igualdade nas idades dos seus integrantes, foi a família punaluana, na qual os irmãos não podiam ter relações sexuais entre si, começando pelos irmãos por parte de mãe e 
posteriormente os irmãos colaterais, ou seja, primos carnais e em segundo e terceiro graus foram excluídos das relações.

Essa redução no número de parceiros e parceiras, deu origem à terceira etapa da organização familiar, a família sindiásmica - que aparece na fase superior do estado selvagem, quase na barbárie -, na qual um homem vivia com uma mulher, sendo direito dos homens a poligamia e a infidelidade ocasional. Assim sendo, o vínculo entre eles se dissolvia com muita facilidade, ficando os filhos, como antes, pertencendo à mãe.

Nesta forma de família, característica da barbárie, introduziram-se na economia familiar: a domesticação dos animais, a criação de gado, a elaboração dos metais, a arte do tecido, a escravidão e, posteriormente, a agricultura. Devido à forma de distribuição dos trabalhos que incumbia o homem de obter o alimento para a família, caso houvesse separação, as riquezas ficavam pertencentes a ele. De acordo com o direito materno, uma vez que a descendência se contava por linha feminina, os bens do pai ficavam como herança aos seus irmãos e sobrinhos e não aos seus filhos. Este fato desencadeou, segundo Engels, uma das mais profundas revoluções que a humanidade já conheceu: a substituição do direito hereditário materno pela filiação paterna e o direito hereditário dos homens (pais).

O desmoronamento do direito materno, a grande derrota do sexo feminino em todo o mundo. O homem apoderou-se também da direção da casa; a mulher viu-se degradada, convertida em servidora, em escrava da luxúria do homem, em simples instrumento de reprodução. Essa baixa condição da mulher, manifestada sobretudo entre os gregos dos tempos heróicos e, ainda mais, entre os dos tempos clássicos, tem sido gradualmente retocada, dissimulada e, em certos lugares, até revestida de formas de maior suavidade, mas de maneira alguma suprimida (ENGELS, 1985: 61).

Stearns retoma o tema trabalhado por Engels, dando uma noção de tempo, fato que o livro de Engels não apresenta, vindo a completá-lo.

Por volta do quarto milênio a.e.c., também, a maior parte das sociedades agrícolas tinha desenvolvido novas formas de desigualdades entre homens e mulheres, num sistema geralmente chamado de patriarcal - com o domínio de maridos e pais. As civilizações, de uma forma geral, aprofundaram o patriarcado e, ao mesmo tempo, definiram seus detalhes de formas distintas que combinavam com crenças e instituições mais amplas de cada civilização em particular. Nesse sentido, pondo um selo próprio no patriarcado, cada civilização uniu as questões de gênero com aspectos de sua estrutura cultural e institucional (STEARNS, 2007: 27). 
Derivada da família sindiásmica "pós-revolução", a última etapa da organização familiar é a família monogâmica que se iguala à sindiásmica na estrutura e direito à infidelidade masculina - responsável pelas formas claras de prostituição -, reprimindo severamente a mulher caso esta seja infiel. Só o homem pode romper com o matrimônio. O homem tem como finalidade expressa a procriação e sustento dos filhos. Como muitos tinham as escravas como concubinas e outros tantos tomavam uma segunda esposa, caso a primeira fosse estéril, a monogamia era monogamia só para a mulher e não para o homem.

Um triunfo da propriedade privada sobre a comum primitiva, a monogamia foi a primeira forma de família baseada em condições econômicas, ao contrário das anteriores que se baseavam em condições "naturais". Engels acentua que

O primeiro antagonismo de classes que apareceu na história coincide com o desenvolvimento do antagonismo entre o homem e a mulher na monogamia; e a primeira opressão de classes, com a opressão do sexo feminino pelo masculino. A monogamia foi um grande progresso histórico, mas, ao mesmo tempo, iniciou, juntamente com a escravidão e as riquezas privadas, aquele período, que dura até nossos dias, no qual cada progresso é simultaneamente um retrocesso relativo, e o bem-estar e o desenvolvimento de uns se verificam às custas da dor e da repressão de outros (ENGELS, 1985: 70-71).

As ponderações de Engels são importantes, também, para que se reflita sobre outras figuras sociais, arregimentadas pelo tipo de família monogâmica - notadamente, "o amante da mulher casada" e "o marido corneado" - figuras que deram vida a diversas personagens, celebrizadas pela literatura em todo o mundo.

\section{A HEGEMONIA SOCIAL, RELIGIOSA E BIOLÓGICA}

Ao discutir a questão da indissolubilidade do matrimônio, Engels postula que esta é

consequência, em parte, das condições econômicas que engendraram a monogamia e, em parte, uma tradição da época em que, mal compreendida ainda, a vinculação dessas condições econômicas com a monogamia foi exagerada pela religião (ENGELS, 1985: 90). 
E, no que diz respeito à religião, as mulheres sempre foram mais participativas que os homens. No entanto, segundo Rosado-Nunes, têm-se uma visão equivocada de que as mulheres são mais religiosas que os homens:

$\mathrm{Na}$ verdade, as religiões são um campo de investimento masculino por excelência. Historicamente, os homens dominam a produção do que é "sagrado" nas diversas sociedades. Discursos e práticas religiosas têm a marca dessa dominação. Normas, regras, doutrinas são definidas por homens em praticamente todas as religiões conhecidas. As mulheres continuam ausentes dos espaços definidores das crenças e das políticas pastorais e organizacionais das instituições religiosas. O investimento da população feminina nas religiões dá-se no campo da prática religiosa, nos rituais, na transmissão, como guardiãs da memória do grupo religioso (ROSADONUNES, 2005: 363).

As constatações de Rosado-Nunes confirmam a afirmação de Engels de que era economicamente benéfico para as igrejas que os casais permanecessem unidos e vivendo dentro da doutrina destas, contribuindo financeiramente segundo o costume de cada uma. Também conclui-se que os homens utilizavam e utilizam a igreja para manipular a consciência feminina, visto que as mulheres participam das cerimônias e ritos religiosos produzidos pelos homens. A religião ajuda a preservar o sistema familiar monogâmico.

As considerações engelianas sobre a família monogâmica lançam luz para que se compreendam as relações matrimoniais entre as personagens, presentes na obra literária de Kate Chopin, uma vez que, tratando do progresso da família e da sociedade, Engels (1985: 91) valendo-se de Morgan, vai enfatizar que "a família é produto do sistema social e refletirá o estado de cultura desse sistema".

A importância de autoras como Chopin se dá para romper com padrões sociais desiguais. Para Bordieu (1999: 17) a divisão entre os sexos é tão usual e tão presente que parece estar "na ordem das coisas". No mundo social, ela legitima posições de diferença e preconceito, configurando-se como instância de "dominação masculina".

A força da ordem masculina se evidencia no fato de que ela dispensa justificação: a visão androcêntrica impõe-se como neutra e não tem necessidade de se enunciar em discursos que visem a legitimá-la. A ordem social funciona como uma imensa massa simbólica que tende a ratificar a 
dominação masculina sobre a qual se alicerça: é a divisão social do trabalho [...]; é a estrutura do espaço, opondo o lugar de assembléia ou de mercado, reservados aos homens, e a casa, reservada às mulheres. [...] A diferença biológica entre os sexos, isto é, entre o corpo masculino e o corpo feminino, e, especificamente, a diferença anatômica entre os órgãos sexuais, pode assim ser vista como justificativa natural da diferença socialmente construída entre os gêneros e, principalmente, da divisão social do trabalho. (BORDIEU, 1999: 18-20).

O autor em foco (1999: 33), chama a atenção, igualmente, para a construção simbólica da ideia de dominação, capaz de acumular e condensar duas operações: legitimar "uma relação de dominação inscrevendo-a em uma natureza biológica que é, por sua vez, ela própria uma construção social naturalizada".

\section{DOMINAÇÃO E LIBERTAÇÃO EM THE STORY OF AN HOUR}

Tendo vivido a experiência de dominação e libertação, Kate Chopin retrata com maestria o lado de quem se vê obrigada a submeter-se aos costumes da sociedade regida pelos homens. Com a força desse atributo, Chopin discute a hegemonia masculina no conto The Story of An Hour (A história de uma hora), tarefa difícil levando-se em consideração o fato de que a personagem principal é feminina.

The Story of An Hour foi escrito em 1894, e conta como Louise Mallard recebeu - com muita cautela, devido aos seus problemas cardíacos - a notícia de que seu marido, Brently, havia morrido em um acidente de trem. De imediato, a personagem chora muito. Mais tarde, sozinha em seu quarto, ela lentamente começa a perceber que apenas libertou-se: "Free! Body and soul free!' she kept whispering” (2002: 757). ${ }^{1}$ Então, quando seu marido repentinamente reaparece, vendo que o relato de sua morte fora um engano, Louise cai morta à vista dele. De "doença cardíaca", disseram os médicos, "da alegria que mata".

1 “'Livre! Corpo e alma livre!' ela continuava sussurrando”. (As traduções são do autor deste ensaio). 
A princípio, a doença de Louise parece natural, uma fragilidade física, porém, quando a personagem principal revela o sentimento de sua alma: "free, free, free" $(2002: 757)^{2}$, entendese porque as linhas de seu rosto "bespoke repression and even a certain strength" (2002: $756)^{3}$, levando o leitor a compreender a relação entre dominação psicológica e doença cardíaca.

Após a morte de Brently, Louise demonstra estar curada dos problemas cardíacos, uma vez que estava liberta da dominação sofrida e, consequentemente, da imanência causada pela hegemonia masculina. "There would be no powerful will bending hers in that blind persistence with which men and women believe they have a right to impose a private will upon a fellow-creature" (2002: 757). ${ }^{4}$ A imanência ou submissão de Louise se revela mesmo no momento de sua libertação, quando ela sente o "it" chegar, e submissamente luta contra isso, deixando-se possuir por essa coisa que posteriormente ela descobre ser o sentimento de liberdade. Uma atitude como a de Louise é compreensível, levando-se em conta a cultura e costumes que a encorajavam ao auto-sacrifício ao invés da auto-realização, frutos da intransigência das estruturas sociais que usavam a tradição e a biologia como subterfúgio para a dominação.

O diagnóstico médico foi a prova cabal da consciência hegemônica da época (fim do século XIX). É evidente que para os médicos - bem como para todos os homens e a grande maioria das mulheres -, uma mulher deveria amar seu marido, a ponto de morrer de emoção caso soubesse que a "fatalidade" de sua morte fora um engano. Bárbara Ewell exprime bem essa ideia de devoção obrigatória ao marido:

To outsiders, Louise Mallard's demise is as misunderstood as is her reaction to Brently's death. That even the respected medical profession misinterprets her collapse indicts the conventional view of female devotion and suggests that Louise Mallard is not the only woman whose behavior has been misread.5 (EWELL, 1986: 90-91).

\footnotetext{
2 “"livre, livre, livre!"”

3 "revelavam repressão e mesmo uma certa resistência".

4 "Não haveria desejo poderoso que a faria curvar-se àquela cega persistência com que homens e mulheres acreditam que têm o direito de impor um desejo particular sobre seu/sua companheira".

5 "Para os estranhos, a morte de Louise Mallard é tão mal entendida quanto sua reação à morte de Brently. Que mesmo a opinião médica respeitada interpreta mal seu colapso aponta para uma visão convencional da devoção feminina e sugere que Louise Mallard não é a única mulher cujo comportamento foi mal interpretado".
} 
É fantástica a habilidade com que Chopin apresenta a hegemonia masculina. Brently somente pratica uma ação no conto - abrir a porta -, no entanto, é perceptível, através das descobertas de Louise, a respeito de seus pensamentos, sonhos e desejos, o quanto esta se auto-reprimia para cumprir com a tradição das mulheres que viviam para satisfazer os homens. Em uma primeira leitura pensa-se que a personagem principal é uma mulher de idade avançada, com complicações cardíacas, contudo, no oitavo parágrafo, o leitor surpreende-se ao descobrir que: "She was young, with a fair, calm face" (2002: 756). ${ }^{6}$ Essa surpresa desperta o leitor, e chama sua atenção para os detalhes, os pressupostos, subentendidos ${ }^{7}$ e outros recursos que o farão compreender o conto de maneira diferente da sociedade hegemônica do final do século XIX.

Kate Chopin criou um narrador que, se não é seu alterego, é outra mulher, pois as descrições e pistas para que se desvende o caráter de Louise são de alguém que compreende sua situação e a perdoa, também mostra como ela descobre a felicidade com a morte do marido e, pela narração, acompanha-se sua luta contra a culpa que a abatia. De uma perspectiva feminina, é possível compreender a morte de Brently como a libertação de um casamento infeliz. Supondo-se que o narrador fosse um homem, a morte de Louise seria interpretada como uma punição por seu sentimento de alegria. Todavia, a sensação causada pela morte de Louise não é, nem de longe, a mesma causada pela morte de Emma Bovary. Pelo contrário, a narração faz refletir sobre a desigualdade ainda existente entre homens e mulheres e era muito mais contundente na época da publicação do conto.

\section{A IMPORTÂNCIA DA PALAVRA E DO NOME}

Verificando-se o discurso de Louise, fica evidente a relação de emancipação e liberdade proveniente do fato da personagem exteriorizar verbalmente os seus sentimentos. Mas, é somente com muito esforço, após uma batalha consigo mesma, que ela consegue verbalizar o que sente. $\mathrm{O}$ ato de nomear o sentimento, proferindo as palavras que o designam, permite a Louise compreendê-lo. É como se ele se personificasse através dela.

\footnotetext{
6 "Ela era jovem, com um rosto claro e calmo".

${ }^{7}$ Os pressupostos e subentendidos do conto serão analisados posteriormente neste ensaio.
} 
Essa atitude da personagem remete às palavras bíblicas do Evangelho segundo São João - "E o Verbo se fez carne e habitou entre nós" (João: 1, 14) -, que, por sua vez, lembram a introdução do Gênesis (1, 1-31) significando que a Palavra é a sabedoria de Deus vislumbrada nas maravilhas do mundo e no desenrolar da história e que Jesus, Palavra de Deus, é a luz que ilumina a consciência de todo homem. Assim, o ato de nomear, o ato de dar vida e o ato da criação estão associados com a palavra de Deus.

Não é à toa, portanto, que ao conseguir exteriorizar o que sente, ao nomear seus sentimentos, Louise está dando vida à nova mulher que, liberta da dominação, começa a surgir lentamente.

O primeiro nome da protagonista só é revelado depois que esta fica sabendo da morte do marido e se sente liberta. Antes disso, Louise só é mencionada como "Sra. Mallard" ou "ela", e, após o retorno do marido, ela é tratada como "sua mulher" (esposa). Com isso Chopin atenta para um fato importante a respeito do título de "esposa": quando Louise casou-se com Brently, ela tornou-se a Sra. Mallard, perdendo sua identidade pessoal e assumindo outra diferente. Embora tal fato pareça natural, a reflexão séria a respeito disso revela que ela tornou-se propriedade do marido, entregando a ele uma parte, se não todo seu ser. Sendo assim, pode-se entender por que a morte do Sr. Mallard lhe despertou sentimentos de liberdade e alegria.

\section{O DESPERTAR}

Semelhante ao conto The Story of An Hour, o romance $O$ Despertar é brilhantemente escrito por Chopin, repleto de imagens e conteúdo social, reflete situações comuns, acontecidas no estado de Louisiana, durante o governo da rainha Vitória - de 1837 a 1901 - o qual, segundo a revista Superinteressante (SEMERENE, 2006: 76) "foi marcado pela austeridade e rigidez dos costumes".

A história se passa no estado de Louisiana, nos Estados Unidos, e gira em torno de duas personagens centrais, o Sr. e a Sra. Pontellier, os quais têm dois filhos, mas levam a vida emocionalmente separados. O Sr. Pontellier é um aristocrata Creole, totalmente absorvido por 
seus negócios, interesses sociais e pretensões da época. Ele constantemente repreende a esposa por ser desatenta e negligente quanto às crianças e as preocupações sobre como isto será percebido pelos outros. É emocionalmente distante das necessidades da esposa e passa o tempo livre longe da família, divertindo-se.

Edna Pontellier, a personagem principal, é uma mulher americana, bastante deslocada em relação aos costumes da sociedade em que se encontra inserida. Almeja um novo começo, um senso de propósito, um despertar da paixão interna. Deseja ser amada por si mesma e aceita como tal pela sociedade. Ela busca, incessantemente, integrar-se consigo mesma; conhecer as potencialidades de seus desejos e dar-lhes vazão.

Sua relação com as crianças, no princípio da história corresponde ao típico dever maternal. Contudo, ela oscila completamente entre o dever e a indiferença, na procura por significados e auto-afirmação.

Em uma das férias de verão dos Pontellier, Edna se encontra com um rapaz chamado Robert Lebrun e eles passam muito tempo juntos. Um laço íntimo é formado entre os dois, até que Robert decide tentar seu futuro trabalhando no México. Edna fica arrasada e busca consolo e apoio nas suas amigas. Porém, acha pouco conforto na companhia delas e volta-se para outro homem jovem, Alceé Arobin. Ela responde a estes avanços românticos em um nível físico, mas não ousa se abrir emocionalmente enquanto espera pelo retorno de Robert.

Edna decide mudar-se, deixar o lar e achar um lugar dela própria, enquanto o marido e as crianças estivessem fora: um movimento para afirmar sua independência e crescente consciência das próprias necessidades. O Sr. Pontellier responde de um modo negativo, pois ele ainda se agarra à convicção de que iriam a uma viagem para o exterior, como forma de reconciliação. Ele protege sua reputação anunciando isto no jornal. Este episódio demonstra, de forma clara, como o Sr. Pontellier é prisioneiro dos costumes sociais daquela época, segundo os quais nenhuma mulher casada abandonaria o lar.

Depois que Robert retorna do México ele ignora Edna que se desespera novamente por causa da sua atitude para com ela. Edna o repreende por sua falta de atenção e ele confessa, finalmente, seu amor. O matrimônio dela era a razão pela qual ele fora para o México. Pela primeira vez, a personagem principal está contente e sua alma atormentada está em paz. Uma amiga de Edna que está dando a luz necessita de sua presença. Então, esta pede a Robert que 
aguarde por seu retorno. Entristecida e exausta pelo sofrimento da amiga, Edna volta para encontrar Robert que já havia ido, deixando-lhe apenas um bilhete, no qual se lia: "Adeus porque eu te amo". Desesperada, ela percebe que agora está totalmente só e, em um último ato de independência e desafio, mergulha no oceano onde ninguém mais poderia possuir seu corpo, nem sua alma. Ela estava, agora, só com seus medos e recordações.

Edna Pontelier se suicida pois a amiga a admoestou sobre o impacto de suas ações sobre os filhos, mas principalmente porque o discurso sobre honra que Robert lhe faz mostra a ela que se divorciar e casar com ele seria apenas trocar de "patrão". Sroczynski acentua que

Publicado em 1899, $O$ despertar surpreende o público e a crítica. Um romance no qual se explora a individualidade da mulher, em que se celebra a sexualidade feminina, em que se discutem as tensões entre as imposições do casamento e os desejos eróticos, em que se questionam os mitos da maternidade, provoca reações hostis considerando-se, principalmente, os arraigados preconceitos sociais e os padrões morais concernentes ao contexto no qual a obra estava inserida. [...] Na época em que o romance foi escrito, o Código Napoleônico ainda era a base legal que regia os contratos matrimoniais. Conforme Culley (1976, p.118), "Todos os bens da mulher, após o casamento, passavam a ser propriedade de seu marido, incluindo dinheiro que ela viesse a ganhar e as roupas que usasse". (SROCZYNSKI, 2004: 10-11).

Da mesma forma que Edna, em $O$ despertar, Louise, em The Story of an Hour também busca a individualidade, aliás, um dos temas principais de Kate Chopin. Quando Louise repete três vezes "livre", não significa que ela se sinta livre para casar com outro, mas que ela está emancipada da dominação masculina. Com a morte do marido sentiu-se livre para viver segundo a sua vontade, pois

she saw beyond that bitter moment a long procession of years to come that would belong to her absolutely. And she opened and spread her arms out to them in welcome. There would be no one to live for during those coming years; she would live for herself (CHOPIN, 2002: 757).8

É louvável a atitude da autora em tentar “despertar” as mulheres da época, sofredoras de tamanha repressão e anulação. Se ainda há desigualdade entre homens e mulheres, pode-se ter

\footnotetext{
8 “ela viu além daquele amargo momento uma procissão de anos vindouros que pertenceriam somente a ela. E abriu os braços para recebê-los. Não haveria ninguém por quem viver naqueles anos à frente; ela viveria para si”.
} 
uma ideia de como era há mais de cem anos, pois até 1977, as mulheres que engravidassem nos Estados Unidos perdiam imediatamente seus empregos. Segundo Muraro (2007: 232), as empresas seguiam o princípio de que tinham "o direito de não prejudicarem sua produção."

Foi somente em 1978 que as americanas conseguiram uma lei que lhes permitiu ficar três meses em casa e, depois, retornarem aos empregos, mas sem receberem salário durante esse período de licença. E isso acontece até hoje, quando a riqueza americana mais que duplicou! (MURARO, 2007: 232).

\section{ANTÍTESES COMO REPRESENTAÇÃO DA ANGÚSTIA FEMININA}

Acostumada a anular-se e reprimir-se em prol do marido, é com angústia que Louise enfrenta esse movimento de libertação, o que pode ser observado pelas metáforas antitéticas da "alegria monstruosa" e do "amor x liberdade/autoafirmação": "She did not stop to ask if it were or were not a monstrous joy that held her" (2002: 757). ${ }^{9}$ Mesmo com o profundo sentimento de alegria, Louise sabia que aos olhos dos demais seria uma coisa monstruosa sentir-se alegre com a morte do marido; "And yet she had loved him [...] What could love, the unsolved mystery, count for in face of this possession of self-assertion which she suddenly recognized as the strongest impulse of her being!” (2002: 757). ${ }^{10}$ A liberdade e autoafirmação sentidas pela protagonista do conto são, como se pode constatar na citação acima, muito mais valiosas se comparadas com o amor sentido pelo marido e sua vivência conjugal.

Outra marca da angústia de Louise são os motivos da morte e do valor à vida. "She breathed a quick prayer that life might be long. It was only yesterday she had thought with a shudder that life might be long" (2002: 758). ${ }^{11}$ A personagem percebe que no dia anterior havia desejado a morte; depois da libertação das correntes da dominação, ela deseja o contrário: quer longos dias para desfrutar a retomada de sua individualidade.

\footnotetext{
9 "Ela não parou para perguntar se era ou não uma alegria monstruosa que a invadia".

10 "E contudo ela o amara [...] O que poderia o amor, o mistério não solucionado, contar diante dessa possessão de autoafirmação que ela repentinamente reconhecera como o impulso mais forte de seu ser!"

11 "Ela suspirou uma rápida prece para que a vida fosse longa. Justamente ontem ela pensou com estremecimento que a vida poderia ser longa".
} 


\section{RECURSOS LINGUÍSTICO-DISCURSIVOS: O LEITOR COMO PARCEIRO DA} ENUNCIAÇÃO

Há, no conto em análise, grande utilização de recursos linguístico-discursivos como forma de expressar a linguagem do desejo da libertação. Um desses recursos corresponde à utilização sinestésica de elementos da natureza que se integram à forma como a personagem capta e exprime suas reações e sentimentos, após a morte do marido. Repentinamente, tudo passa a ter um significado diferente, semelhante a um espelhamento do interior (da personagem) no exterior (natureza, ambiente).

A sinestesia, que influencia Louise através dos perfumes, cores, sons exteriores - o aroma da chuva, uma canção que se junta ao canto dos pássaros e ao grito do sacoleiro, as manchas de céu entre as nuvens - contribuem para o insight, a revelação de seus sentimentos. Mas, tal revelação adquire um valor maior. $O$ fato de ter vindo do céu, atribui um valor "sobrenatural" ao ocorrido. Mais do que puramente física, corpórea, a libertação tem importância espiritual. "But she felt it, creeping out of the sky, reaching toward her through the sounds, the scents, the color that filled the air" (2002: 757). ${ }^{12}$

A liberdade é afirmada como valor primordial: "possessão de autoafirmação". Louise Mallard tem como objetivo de vida a liberdade para viver à sua maneira, seguindo suas próprias convicções. No entanto, antes deste libertar-se, era o amor o propósito principal de sua vida. Através da metáfora antitética do amor x liberdade/autoafirmação, complementada com a metáfora sinestésica, pode-se afirmar que Louise compreende seu real valor. Como afirma Ewell:

But Chopin also exposes Louise's complicity in Mallard's subtle oppression. Her submission to his "blind persistence" has been the guise of Love, that self-sacrificing Victorian ideal. Glorified in fiction Chopin had often decried, this love has been, for Louise and others, the primary purpose of life. But through her new perspective, she comprehends that "love, the unsolved mystery" counts for very little "in face of this possession of selfassertion which she suddenly recognized as the strongest impulse of her

12 "Mas ela o sentiu, vindo sorrateiramente pelo céu, tocando-a através dos sons, dos aromas, da cor que enchia o ar". 
being!" As Chopin often insists, love is not a substitute for selfhood; indeed, selfhood is love's precondition (EWELL, 1986: 89). ${ }^{13}$

Em uma leitura rápida do conto, dificilmente compreender-se-ão os motivos reais da doença e morte de Louise, visto que a dominação/libertação está mais nos pressupostos e subentendidos do que na superfície do texto.

Os pressupostos e subentendidos são importantes para deixar escoar informações relevantes do texto, sem torná-lo enfadonho. Por exemplo, a confirmação de que Louise sentia-se curada aparece pressuposta em “ 'Go away. I am not making myself ill'. No; she was drinking in a very elixir of life through that open window" (2002: 758). ${ }^{14}$

a) Louise afirma que não ficaria doente (conteúdo posto);

b) Para "ficar doente" é necessário estar bem, caso contrário, ela continuaria doente.

Pressupõem-se assim, que Louise tem convicção de que está curada. Tal pressuposição é confirmada com a frase seguinte, que se inicia com a confirmação de que ela não ficaria doente mesmo ("No"), sendo concluída com a explicação do porquê (estava bebendo o elixir da vida). Pressuposição tem a ver com lógica e, para Maingueneau (1996: 100), “o pressuposto desempenha um papel essencial na construção da coerência textual”, e acrescenta, posteriormente:

É impossível que o enunciador saiba exatamente o que é admitido ou não pelo destinatário. Ele é reduzido pelo último a tecer constantemente hipóteses a esse respeito. Essa disparidade entre os saberes do enunciador e do co-enunciador tem uma vertente positiva: o co-enunciador, graças aos pressupostos, tem acesso a um saber do qual era desprovido, além daquele que os conteúdos colocados trazem. (MAINGUENEAU, 1996: 101).

\footnotetext{
${ }^{13}$ Mas Chopin também expõe a cumplicidade de Louise à opressão sutil de Mallard. Sua submissão à sua "cega persistência" tem sido o disfarce do Amor, aquele ideal vitoriano de autoabnegação. Glorificado na ficção que Chopin tem frequentemente condenado (rejeitado), este amor tem sido, para Louise e outras, o propósito principal da vida. Mas através da sua nova perspectiva, ela compreende que aquele "amor, o mistério não solucionado" tem pouco valor "diante dessa possessão de autoafirmação que ela repentinamente reconhecera como o impulso mais forte de seu ser!" Como Chopin frequentemente insiste, o amor não é um substituto da individualidade; na verdade, individualidade é pré-condição do amor.

14 “'Vá embora. Eu não vou ficar doente.' Não; ela estava bebendo o poderoso elixir da vida através da janela aberta".
} 
A explicitação da natureza dos implícitos, especificamente, da presença dos subentendidos, conforme os postulados de Ducrot, lança luz sobre o processo discursivo usado por Kate Chopin. Para o teórico (1987: 41), o subentendido está ligado à enunciação e se explica por um processo interpretativo: "diz respeito à maneira pela qual esse sentido deve ser decifrado pelo destinatário".

Os subentendidos são mais difíceis de predizer, pois não se inscrevem na própria língua, como os pressupostos. Os subentendidos são fatos retóricos ligados à enunciação, ficam nas entrelinhas do discurso.

Quando Louise resolve abrir a porta para sua irmã, "there was a feverish triumph in her eyes, and she carried herself unwittingly like a goddess of Victory" (2002: 758). ${ }^{15}$ É possível inferir que a protagonista sente-se em êxtase por ter vencido a batalha da libertação da dominação, sem que a tenha lutado, e mais, tendo sido conivente com essa situação opressora. É claro que Chopin não podia predizer quais subentendidos essa frase iria liberar, mas sabia que o leitor refletiria a respeito de seu significado ao enunciar que a personagem principal experimentava uma sensação tão boa que a fazia agir inconscientemente como a "deusa da Vitória".

\begin{abstract}
Pressupostos e subentendidos permitem que os locutores digam sem dizer, adiantem um conteúdo sem assumir completamente sua responsabilidade. No caso do pressuposto, existe um recuamento desse conteúdo; no do subentendido, trata-se antes de uma espécie de adivinhação colocada ao coenunciador. Ele deve derivar de proposições baseando-se nos princípios gerais que regem a utilização da linguagem. Esses subentendidos não são, portanto, passíveis de predição fora do contexto, de acordo com os contextos, a mesma frase poderá liberar subentendidos totalmente diferentes (MAINGUENEAU, 1996: 105).
\end{abstract}

Da mesma forma que em The Awakening Chopin trabalha o motivo da circularidade valendo-se da metáfora do mar, em The Story of An Hour, a escritora desenvolve a circularidade metafórica através da doença do coração. A ambiguidade apresentada por tal doença no conto é proposital. Nada melhor que uma doença cardíaca para expressar a repressão causada pela dominação masculina, responsável pela angústia, imanência, impotência e servidão, que caracterizam os "problemas do coração" de Louise.

15 “Havia um triunfo excitante em seus olhos e ela conduziu-se inconscientemente como a deusa da Vitória”. 
No primeiro parágrafo do conto, está demonstrada a forma como todos tomaram cuidado em tratar o acontecimento da morte do Sr. Mallard, com a maior cautela possível, devido aos problemas de coração que afligiam a Sra. Mallard. Bárbara Ewell discute a capacidade de Kate Chopin em lidar com a linguagem ambígua:

Chopin handling of details illustrates how subtly she manages this controversial material. Louise Mallard's heart disease, for example, the key to the final ironies and ambiguities, is introduced in the first sentence, like the loaded gun of melodrama. But her illness gradually deepens in significance from a physical detail - a symptom of delicacy and a reason to break the bad news gently - to a deeply spiritual problem. [...] Indeed, that "trouble" vanishes with Brently's death and returns - fatally - only when he reappears (EWELL, 1986: 89).16

Quando Louise se liberta da dominação de Brently, compreende-se a natureza de sua doença cardíaca que reaparece com o retorno do marido, supostamente morto, encerrando-se com a fatalidade da morte da protagonista e não dele. Morte de doença cardíaca, segundo os médicos, fechando a circularidade do conto com a ironia antitética da "alegria que mata". Tal foi a explicação da hegemonia masculina para o infarto de Louise.

\section{CONCLUSÃO}

As metáforas contrastivas, a circularidade - remetendo o motivo final ao motivo inicial -, a presença da sinestesia - em que a posse da liberdade está associada e se expressa pelas sensações olfativas, visuais e termais - fazem parte de um tipo de discurso que, de forma ambígua, se inscreve na interpretação do leitor ou co-enunciador e, nesse sentido, refere-se ao subentendido.

${ }^{16}$ A forma como Chopin conduz os detalhes ilustra quão sutilmente ela lida com esse assunto controverso. A doença cardíaca de Louise Mallard, por exemplo, a chave para as ironias finais e ambiguidades, é introduzida na primeira sentença, como a arma carregada de melodrama. Mas sua doença gradualmente se aprofunda em significado, de um detalhe físico - um sintoma de delicadeza e uma razão para dar-lhe as más notícias gentilmente - a um problema profundamente espiritual. [...] De fato, aquele "problema" termina com a morte de Brently e retorna - fatalmente - somente quando ele reaparece. 
Essa estratégia de Kate Chopin - usar o discurso do subentendido - pode ser explicada devido ao contexto da época em que o conto foi escrito, o qual impedia uma mulher de ter atitudes libertárias. Ela devia servir ao marido e aos filhos e jamais pensar em si própria. Neste conto, a autora ainda deixa sua mensagem velada, para evitar a reprovação e repressão que sofreu ao falar abertamente - em $O$ despertar - sua opinião referente ao direito de liberdade da mulher.

Entretanto, mesmo ainda não tendo declarado abertamente sua insatisfação quanto à posição da mulher na sociedade patriarcal em que vivia, subjacente às estratégias utilizadas no conto, inscreve-se a ironia com que a autora lança luz sobre os preconceitos e, passando por cima da aparente verdade científica - exemplificada pelo atestado com que os médicos justificaram a causa da morte de Louise -, faz do leitor o verdadeiro parceiro da enunciação, podendo ter advindo de suas leituras muitas mulheres com coragem suficiente para se libertarem e muitas outras autoras empenhadas em fazer deste mundo um lugar mais justo, igual e livre.

\section{REFERÊNCIAS:}

BÍBLIA. Português. Bíblia Sagrada. Tradução: Centro Bíblico Católico. São Paulo: Loyola, 1989.

BOURDIEU, Pierre. A dominação masculina. Tradução: Maria Helena Kühner. Rio de Janeiro: Bertrand Brasil, 1999.

CHOPIN, Kate. Complete Novels and Stories. New York: The Library of America, 2002.

DUCROT, Oswald. $O$ dizer $e$ o dito. Revisão da tradução: Eduardo Guimarães. Campinas: Pontes, 1987.

ENGELS, Friedrich. A origem da família, da propriedade privada e do estado. Tradução: Leandro Konder. 10. ed. Rio de Janeiro: Cia. Brasileira, 1985.

EWELL, Bárbara C. Kate Chopin. New York: The Ungar Publishing Company, 1986.

MAINGUENEAU, Dominique. Pragmática para o discurso literário. Tradução: Maria Appenzeller; Revisão da tradução: Eduardo Brandão. São Paulo: Martins Fontes, 1996. 
MURARO, Rose Marie (Org). Mulher e sustentabilidade. In: Muraro, Rose Marie. Série Leituras do Brasil. A vida que a gente quer depende do que a gente faz. São Paulo: Instituto ECOFUTURO, 2007, p. 230-236.

ROSADO-NUNES Maria J. Gênero e religião. Estudos Feministas. Florianópolis,v. 13, n. 2, p. 363-365, maio/ago. 2005.

SEMERENE, Barbara. Amores que mudaram o mundo. Superinteressante, São Paulo, v. 223, p. 74-78, fev. 2006.

SROCZYNSKI, Maria Eloisa Z. Uma análise linguístico-discursiva de O Despertar de Kate Chopin. 2004. 113f. Dissertação (Mestrado em Letras) - UCPel, Pelotas. 2004.

STEARNS, Peter N. História das relações de gênero. Tradução: Mirna Pinsky. São Paulo: Contexto, 2007.

RECEBIDO EM: 07 de maio de 2012

APROVADO EM: 04 de junho de 2012 